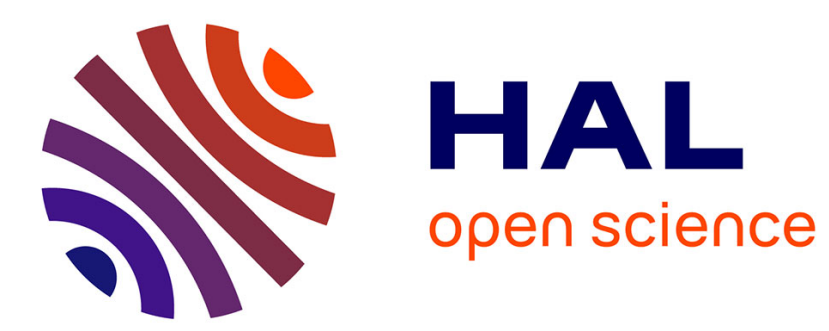

\title{
ADIABATIC SHEAR UNDER BIAXIAL STRESS CONDITIONS IN SHEET METAL FORMING PROCESSES
}

\author{
L. Luo, B. Dodd
}

\section{- To cite this version:}

L. Luo, B. Dodd. ADIABATIC SHEAR UNDER BIAXIAL STRESS CONDITIONS IN SHEET METAL FORMING PROCESSES. Journal de Physique IV Proceedings, 1991, 01 (C3), pp.C3-775C3-780. 10.1051/jp4:19913109 . jpa-00249911

\section{HAL Id: jpa-00249911 https://hal.science/jpa-00249911}

Submitted on 1 Jan 1991

HAL is a multi-disciplinary open access archive for the deposit and dissemination of scientific research documents, whether they are published or not. The documents may come from teaching and research institutions in France or abroad, or from public or private research centers.
L'archive ouverte pluridisciplinaire HAL, est destinée au dépôt et à la diffusion de documents scientifiques de niveau recherche, publiés ou non, émanant des établissements d'enseignement et de recherche français ou étrangers, des laboratoires publics ou privés. 


\title{
ADIABATIC SHEAR UNDER BIAXIAL STRESS CONDITIONS IN SHEET METAL FORMING PROCESSES
}

\author{
L.M. LUO and B. DODD \\ Department of Engineering, University of Reading, \\ Whiteknights, P.O. Box 225, Reading RG6 2AY, Great-Britain
}

\begin{abstract}
Résumé - A l'aide d'une analyse générale tridimensionnelle par perturbation de l'écoulement plastique développée par les auteurs, un critère d'instabilité en cisaillement adiabatique est obtenu, pour des conditions de contraintes biaxiales. Ce critère est ensuite appliqué aux procédés de mise en forme dynamique de tôles. La localisation des instabilités critiques est en bon accord avec les données expérimentales. Les directions de rupture par cisaillement coincident également avec celles prédites pour linstabilité.
\end{abstract}

Abstract-A criterion for adiabatic shear instability under biaxial stress conditions is obtained using the results of a general three dimensional perturbation analysis of plastic flow developed by the authors. The criterion is then applied to dynamic sheet metal forming processes. The critical instability loci are obtained which are in good agreement with experimental data. Also the shear failure directions coincide with those predicted for instability.

\section{Introduction}

Plastic flow under plane stress conditions can be used to model many sheet metal forming processes. The instability and localization of the plastic flow marks the forming limit of the sheet metal. To analyse the instability and localization of plastic flow, Swift/1/ and Hill/2/ derived criteria for the so-called diffuse and localized necking, respectively. Their cases were quasi-static, isothermal with a geometrical softening effect. In another approach, Clifton/3/ and $\mathrm{Bai} / 4 /$ used linear perturbation methods and obtained the criteria of plastic instability in one-dimensional shear. Their aim was to describe the onset of a shear band taking into account thermal and inertial effects but no geometrical effects. However the common subject is the instability of plastic flow. Later Anand et al/5/ generalized the perturbation analysis for three dimensional cases but only presented criteria in plane motion cases due to mathematical difficulties. In previous work Luo and Dodd/6/ obtained instability criteria for plastic flow in three dimensional stress states through a further assumption based on Anand and co-workers' analysis. The results showed the nature of the shear control of instability.

In this paper we apply the general criterion to dynamic sheet metal forming processes under biaxial stress conditions. The main concern here is dynamic 
plastic flow with a point imperfection and a thermal effect but no geometrical effect, which is different from the cases considered by Swift/1/ and Hill/2/. The loci of critical strains in the principal strain plane are derived, (This is the so-called " Forming Limit Diagram ", and the growth rates of imperfections or disturbances. These results are compared with experimental data.

2. Analysis

The governing equations for general deformation processes are balances of mass, momentum and energy, and the constitutive relation. Neglecting the effects of elasticity and body forces and assuming the material to be isotropic, viscoplastic and incompressible, the governing equations are given as follow

$$
\begin{aligned}
& \partial \mathrm{v}_{\mathrm{i}} / \partial \mathrm{x}_{\mathrm{i}}=0 \\
& \rho \partial \mathrm{v}_{\mathrm{i}} / \partial \mathrm{t}=\partial \sigma_{\mathrm{ij}} / \partial \mathrm{x}_{\mathrm{j}} \\
& \rho \mathrm{C}_{\mathrm{v}} \partial \theta / \partial \mathrm{t}=\mathrm{K} \Delta \theta+ \\
& \mathrm{S}_{\mathrm{ij}}=\frac{2 \bar{\tau}}{\bar{\gamma}^{\prime}} \mathrm{D}_{\mathrm{ij}} \\
& \bar{\tau}=\mathrm{f}\left(\bar{\gamma}^{\prime}, \bar{\gamma}, \theta\right)
\end{aligned}
$$$$
\rho \mathrm{C}_{\mathrm{v}} \partial \theta / \partial \mathrm{t}=\mathrm{K} \Delta \theta+\omega \sigma_{\mathrm{ij}} \mathrm{D}_{\mathrm{ij}}
$$

where $v_{i}$ are the velocity components, $\rho$ the material density, $\sigma_{i j}$ the Cauchy stress, $C_{v}$ the specific heat, $\theta$ the absolute temperature, $K$ the thermal conductivity, $\omega$ the fraction of plastic work that is converted into heat, $D_{i j}=\frac{1}{2}\left(\frac{\partial v_{i}}{\partial x_{j}}+\right.$ $\frac{\partial v_{j}}{\partial x_{i}}$, the stretch tensor, $S_{i j}=\sigma_{i j}-\frac{1}{3} \sigma_{k k} \delta_{i j}$, the stress deviator, $\bar{\tau}=\sqrt{\frac{1}{2} S_{i j} S_{i j}}$, the equivalent shear stress, $\bar{\gamma}^{\prime}=\sqrt{\frac{1}{2} D_{i j} D_{i j}}$ the equivalent shear strain-rate, $\bar{\gamma}=\int_{0}^{t} \bar{\gamma}^{\prime} \mathrm{dt}$, the equivalent shear strain. Equations (1)-(5) allow an homogeneous solution that is an homogeneous plastic flow.

Previously, the critical conditions for infinitesimal disturbances to grow were derived, that is the instability of homogeneous plastic flow, in a three dimensional stress state. To apply these conditions to dynamic sheet metal forming processes we use the adiabatic approximation. The criterion is then given by

$$
\mathrm{B}_{\min }<0
$$

where $\mathrm{B}=\rho \mathrm{C}_{\mathrm{v}} \mathrm{Q} \delta_{1}-\left(2 \delta_{1}-1\right) \omega \bar{\tau} \mathrm{T}, \mathrm{Q}=\partial \mathrm{f} / \partial \bar{\gamma}$ is strain hardening rate, $\mathrm{T}=-\partial \mathrm{f} / \partial \theta$ thermal softening rate, $\mathrm{R}=\partial \mathrm{g} / \partial \bar{\gamma}^{\prime}$ strain-rate hardening rate, and $\delta_{1}=\chi \alpha_{\mathrm{s}}$, where

$$
\begin{aligned}
& \chi=4 n_{1}{ }^{2} n_{2}{ }^{2} \\
& \alpha_{s}=\left(\frac{\alpha_{1}-\alpha_{2}}{\bar{\gamma}^{\prime}}\right)^{2}=\left(\frac{s_{1}-s_{2}}{2 \bar{\tau}}\right)^{2} .
\end{aligned}
$$

As disturbances are described by

$$
\widetilde{\zeta}=\zeta_{*} \cdot \exp (i \xi \times n+\eta \Delta t)
$$


where $\xi$ can be stress, stretch, or temperature, for example. $\mathbf{n}_{1}, \mathbf{n}_{2}$ are components of $n$ along the principal stress or stretch axes and $n_{1}{ }^{2}+n_{2}{ }^{2}=1$. Let $\mathrm{n}_{1}=\sin \psi$, then $\mathrm{n}$ is the direction of angle $\psi$ from the $\mathrm{x}_{1}$ direction in the $\mathrm{x}_{1}-\mathrm{x}_{2}$ plane. The magnitude of the disturbances are perpendicular to $n . \alpha_{1}, \alpha_{2}$ and $s_{1}, s_{2}$ are principal stretches and deviatoric stresses respectively. For any fixed ratio of stretch or stress, $\alpha_{s}$ has three possible values, the biggest one is

$$
\alpha_{s}^{*}=\left(\frac{\alpha_{1}-\alpha_{2}}{\bar{\gamma}^{\prime 0}}\right)^{2}=\left(\frac{s_{1}-s_{2}}{2 \bar{\tau}^{0}}\right)^{2}
$$

if $\alpha_{1}, s_{1}$ and $\alpha_{2}, s_{2}$ are the largest and the smallest stretch and deviatoric stress, respectively. From (6) it follows that the biggest $\delta_{1}$ gives the minimum $B$. That requires

$$
\chi=1(\text { or } \psi= \pm \pi / 4) \text { and } \alpha_{s}=\alpha_{s}{ }^{*}
$$

This represents the maximum shear directions, along these directions $B=B_{\min }=\left(2 \alpha_{s}{ }^{*}-1\right) \omega \bar{\tau} T-\rho C_{v} Q \alpha_{s}{ }^{*}$. In fact disturbances will grow in any direction that makes $B$ negative. The initial growth rate is given by

$$
\eta=-\frac{B}{\rho\left[\omega T \bar{\gamma}^{\prime} / \xi^{2}+\delta_{1} C_{v} R+C_{v}\left(1-\delta_{1}\right) \bar{\tau} / \bar{\gamma}^{\prime}\right]}
$$

As usually $\bar{\tau} / \bar{\gamma}^{\prime}>R$, the bigger $\delta_{1}$ the more positive $\eta$ is when $B<0$, thus the disturbances that first grow and have the biggest growth rates along the maximum shear directions. Disturbances of longer wavelength grow faster. The effect of strain-rate hardening reduces the growth rate.

Consider a sheet metal undergoing quick homogeneous plastic flow under biaxial loading, see Fig. 1 and assume $D$ is constant, i.e. constant stretching.

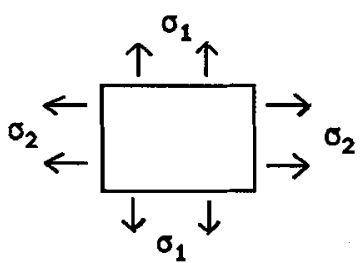

Fig. 1

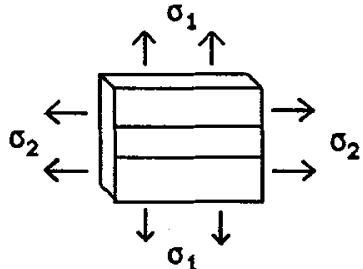

(a)

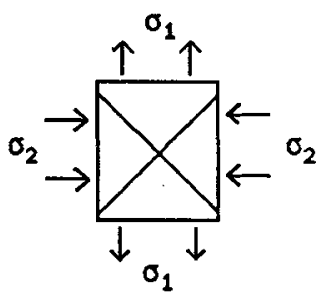

(b)

Fig. 2

Then the spectral form of the stress deviator and the stretch tensor are given as follows

$$
\begin{aligned}
& \mathbf{S}=\left(\begin{array}{lll}
s_{1} & 0 & 0 \\
0 & s_{2} & 0 \\
0 & 0 & s_{3}
\end{array}\right) \\
& \mathbf{D}=\left(\begin{array}{ccc}
\alpha_{1} & 0 & 0 \\
0 & \alpha_{2} & 0 \\
0 & 0 & \alpha_{3}
\end{array}\right)
\end{aligned}
$$


where $s_{1}=\frac{2 \sigma_{1}-\sigma_{2}}{3}, s_{2}=\frac{2 \sigma_{2}-\sigma_{1}}{3}$ and $s_{3}=-\frac{\sigma_{1}+\sigma_{2}}{3}$. Incompressibility requires $\alpha_{1}+\alpha_{2}+$ $\alpha_{3}=0$. Integration of principal stretches gives us logarithmic strains

$$
e_{1}=\alpha_{1} t, e_{2}=\alpha_{2} t \text { and } e_{3}=\alpha_{3} t
$$

If the material can be described by a constitutive equation of the following type

$$
\bar{\tau}=\mu \bar{\gamma}^{\prime m} \bar{\gamma}^{\mathrm{n}} \theta^{v}
$$

Then we have the homogeneous solution of the governing equations (1)-(4) and (16) represented by (13), (14) and

$$
\theta^{1-v}=\theta_{0}^{1-v}+\frac{(1-v) \omega \mu}{(1+n) \rho C_{v}} \bar{\gamma}^{\prime} m \bar{\gamma}^{n+1}
$$

where $\theta_{0}$ is the initial temperature.

From (16) we have

$$
\mathrm{Q}=\mathbf{n} \bar{\tau} / \bar{\gamma}, \mathrm{T}=-\mathrm{v} \bar{\tau} / \theta \text { and } \mathrm{R}=\mathrm{m} \bar{\tau} / \bar{\gamma}^{\prime}
$$

From (6) using (16),(17) and (18), we obtain

$$
\bar{\gamma}>\bar{\gamma}_{\mathrm{c}}
$$

where $\bar{\gamma}_{c}$ is the critical equivalent shear strain for instability and

$$
\bar{\gamma}_{\mathrm{c}^{\mathrm{n}+1}}=\frac{\alpha_{\mathrm{s}}^{*} \rho \mathrm{C}_{\mathrm{v}}(1+\mathrm{n}) \mathrm{n} \theta_{0}{ }^{1-v} \bar{\gamma}^{\prime-m}}{\left[(-\mathrm{n}-\mathrm{n} v-2 v) \alpha_{\mathrm{s}}^{*}+(1+\mathrm{n}) v\right] \omega \mu}
$$

To show it in the $\mathrm{e}_{1}-\mathrm{e}_{2}$ plane, let $\alpha=\mathrm{e}_{2} / \mathrm{e}_{1}=\mathrm{s}_{2} / \mathrm{s}_{1}=\alpha_{2} / \alpha_{1}$. Notice that $\alpha_{1}+\alpha_{2}+\alpha_{3}=1$, we have

$$
\bar{\gamma}=2 \sqrt{1+\alpha+\alpha^{2}} \mathrm{e}_{1}
$$

Replacing $\bar{\gamma}_{c}$ by $e_{1 c}$ in (20) results in

$$
\mathrm{e}_{1 \mathrm{c}^{\mathrm{n}+1}}=\frac{\alpha_{\mathrm{s}}^{*} \rho \mathrm{C}_{\mathrm{v}}(1+\mathrm{n}) \mathrm{n} \theta_{0}{ }^{1-v} \bar{\gamma}^{\prime}-\mathrm{m}}{\left[\alpha_{\mathrm{s}}{ }^{*}(-\mathrm{n}-\mathrm{n} v-2 v)+(1+\mathrm{n}) v\right] \omega \mu}\left(2 \sqrt{1+\alpha+\alpha^{2}}\right)^{-(\mathrm{n}+1)}
$$

where

$$
\alpha_{s}^{*}=\frac{(2+\alpha)^{2}}{4\left(1+\alpha+\alpha^{2}\right)} \text { if } \sigma_{2} \geq 0, \text { thus }-\frac{1}{2}<\alpha<1
$$

and

$$
\alpha_{\mathrm{s}}^{*}=\frac{(1-\alpha)^{2}}{4\left(1+\alpha+\alpha^{2}\right)} \text { if } \sigma_{2}<0 \text {, thus }-1<\alpha<-\frac{1}{2}
$$

The plastic work done at $\bar{\gamma}$ is given by

$$
w=\rho c_{v}\left(\theta-\theta_{0}\right) / \omega
$$

The directions of biggest growth rate for disturbances are shown in Fig.2.

Using values of constitutive parameters of a cold rolled steel

$$
\mu=3579 \times 10^{6}, v=-0.38, \quad m=0.019, \quad n=0.015
$$

with $\rho=7.8 \times 10^{3} \mathrm{~kg} / \mathrm{m}^{3}, \mathrm{C}_{\mathrm{v}}=500 \mathrm{~J} / \mathrm{kgK}, \theta_{0}=300 \mathrm{~K}, \omega=0.9$, the loci of instability or FLD are shown in Fig.3. The critical strain is very sensitive to the strain hardening rate. A bigger $\mathrm{n}$ enhances the critical strain substantially. Higher 
strain-rate reduces the critical strain, but the effect is relatively small. Comparing with the experimental results in Fig.4 (From Maciniack/7/), the shape of these curves is very close to that of the shear failure lines.

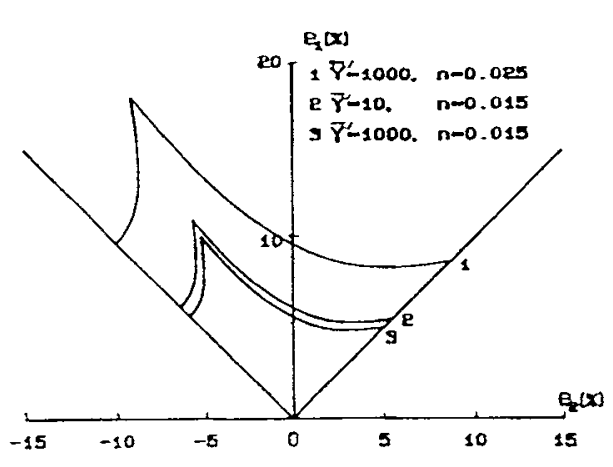

Fig.3

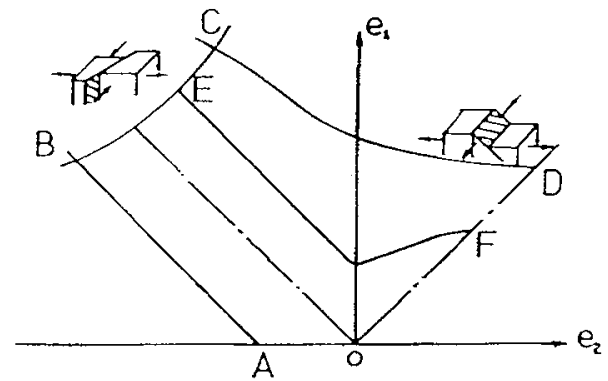

Fig.4 From Maciniak/7/, AB-wrinckling, BCD-Shear failure, EF-necking.

Fig.5 shows the effect of different stress ratios on the critical equivalent shear strain and temperature rise at the critical strain. The values are taken for constant stretching and equivalent shear strain-rate $\bar{\gamma}^{\prime}=101 / \mathrm{s}$. The stress ratio $\beta$ $=\frac{\sigma_{2}}{\sigma_{1}}=\frac{2+\alpha}{2 \alpha+1}$. Different loading ratios affect the critical strain and temperature rise. The highest value is attained at $\alpha=1$ and $\alpha=-0.5$ that is the balanced biaxial tension and uniaxial tension.

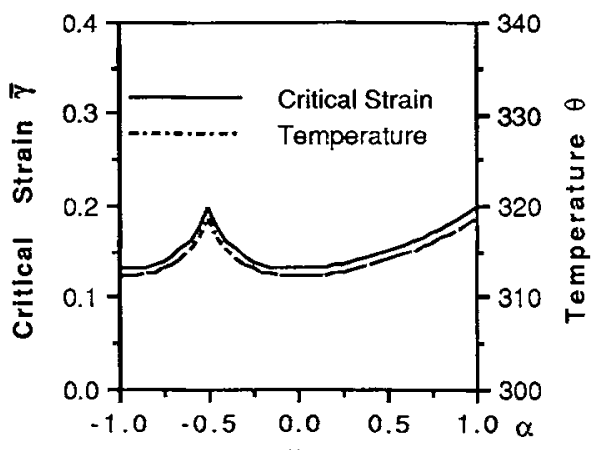

Fig. 5

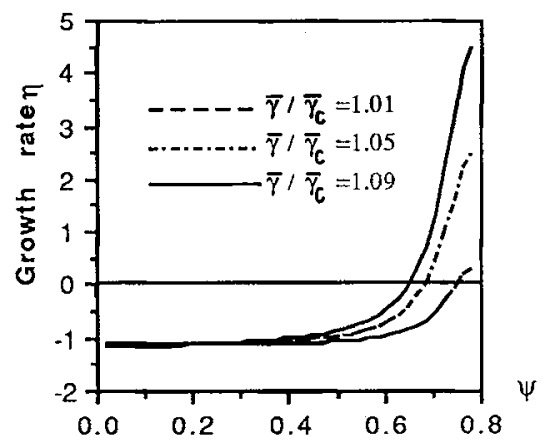

Fig.6

The growth of disturbances is important to the localization of deformation. To see the effects of parameters on growth of disturbances, let us consider eq.(12). Since the typical size of disturbances or defects in metals is less than $0.1 \mathrm{~mm}$, the wave number $\xi$ of disturbances is then bigger than $10^{4} 1 / \mathrm{m}$. This makes $\omega T \bar{\gamma}^{\prime} / \xi^{2}$ much smaller than $\delta_{1} C_{v} R+C_{v}\left(1-\delta_{1}\right) \bar{\tau} / \bar{\gamma}^{\prime}$, thus negligible. Then (12) becomes 


$$
\eta=-\frac{\mathrm{B}}{\rho C_{\mathrm{v}}\left[\delta_{1} \mathrm{R}+\left(1-\delta_{1}\right) \bar{\tau} / \bar{\gamma}^{\prime}\right]}
$$

Fig. 6 shows $\eta$ for different $\psi$ and strain $\bar{\gamma}$. Only in a band of angle near the maximum shear directions, the disturbances may grow and the growth rate increases as the angle becomes close to the maximum shear directions. This makes the growth of disturbances concentrate more and more in the maximum shear direction, these directions are the directions of localization. The growth rate increases with the increasing strain, see Fig.7.

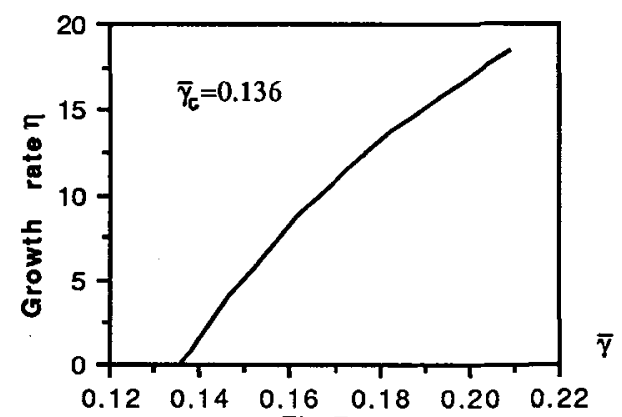

Fig.7

\section{Conclusions}

Instability loci for a deforming sheet metal subjected to biaxial stress conditions are obtained for a rigid-viscoplastic material taking into account thermal effects but no geometrical effects. They are in good agreement with experimental data in shape. The directions of localization coincide with experimental shear failure directions. Higher strain hardening rates enhance the critical strain and higher strain-rates reduce the critical strain.

References

/1/ Swift,H.W., J. Mech. Phys. Solids 1(1952)1

12/ Hill,R., J. Mech. Phys. Solids 1(1952)19

13/ Clifton,R.J., Material Response to Ultrahigh Loading Rates. National Materials Advisory Board Report NMAB-356(1980) 128

/4/Bai,Y.L., J. Mech. Phys. Solids 30(1982)195

/5/Anand,L., Kim,K.H. and Shaw,T.G., J. Mech. Phys. Solids 35(1987)407

/6/Luo,L.M. and Dodd,B., submitted to J. Mech. Phys. Solids

17/Marcinaik,Z., Proc. 1st Int. Conf. on Technology of Plasticity.(1984)685 